\title{
(2) OPEN ACCESS \\ The Columbus steerable guidewire in neurointerventions: early clinical experience and applications
}

\author{
Alexander von Hessling, Tomás Reyes del Castillo (D) , Grzegorz Karwacki, \\ Justus E. Roos
}

Department of Radiology and Nuclear Medicine, Luzerner Kantonsspital Zentrumsspital, Luzern, Switzerland

\section{Correspondence to} Dr Tomás Reyes del Castillo, Department of Radiology and Nuclear Medicine, Luzerner Kantonsspital Zentrumsspital, Luzern 6000, Switzerland; tomas.reyesdelcastillo@luks.ch

Received 17 February 2021 Revised 14 April 2021 Accepted 19 April 2021

\section{Check for updates}

C) Author(s) (or their employer(s)) 2021. Re-use permitted under CC BY-NC. No commercial re-use. See rights and permissions. Published by BMJ.

To cite: von Hessling A, Reyes del Castillo T, Karwacki G, et al.

$J$ Neurolntervent Surg Epub ahead of print: [please include Day Month Year]. doi:10.1136/

neurintsurg-2021-017296

\section{ABSTRACT}

Objective To report our early experience in using the steerable 'Columbus' guidewire, also known as 'Drivewire' in the USA, and its potential applications in neurovascular interventions.

Methods Neurointerventions in 36 patients (20 female, 16 male) using the steerable Columbus guidewire were recorded from August 2019 to December 2020 and included a variety of neurovascular procedures: Treatment of aneurysms ( $n=17)$, thrombectomy in acute ischemic stroke $(n=12)$, and others $(n=7)$, such as treatment of stenosis and embolization procedures. Immediate followup with digital subtraction angiography and tracking of each patient's clinical outcome was performed.

Results In 35 out of 36 cases, the target vessel was reached with Columbus, including advancement of the appropriate microcatheter. In 14 cases, additional wires were used, mainly because of the nature of the procedures (eg, use of multiple wires/buddy wires or exchange maneuvers). In five cases, the Columbus wire was damaged by the operator and had to be replaced. Peri-interventional complications occurred in two patients, neither attributed to the Columbus guidewire. Conclusions The new Columbus neurovascular guidewire has the unique ability to be shaped within the patient. Currently available versions lack torquability compared with other available guidewires but offer tremendous support at the tip, allowing maneuvers which are impossible with other wires on the market.

\section{INTRODUCTION}

Neuro guidewires have been used for decades, with sizes ranging from 0.007" to (typically) 0.014", to navigate microcatheters to the anatomic site where they are needed. They differ in size, degree of stiffness, visibility in fluoroscopy, steerability, trackability, torque, and their ability to be shaped. The tip of the wire is usually straight at first and is shaped manually by the interventionists as necessary to facilitate navigation to the desired location in the cerebral vessel. Navigation in the vasculature is generally executed by torqueing the wire using the end outside of the patient with a combination of wire and catheter movements. ${ }^{1}$ However, the shape of the tip is lost over time and cannot be manipulated in a controlled fashion while it is inside the vessel. In addition, the support of the wire tip is usually weak, and so the microwire usually has to be advanced quite far into the vasculature before it becomes supportive enough to assist a microcatheter in navigating sharp turns. Inappropriate and inconsistent wire shape, as well as the inability to reshape the tip of a guidewire in situ, are the most common causes of guidewire exchange in neurovascular intervention, which leads to loss of momentum, position, and time.

Techniques for hydraulically or magnetically steerable micro guidewires are described in the literature. ${ }^{23}$ However, to our knowledge, neither technique has been CE-marked or used in humans in clinical scenarios for the treatment of cerebrovascular pathologies to date.

Two common tasks for neuro guidewires (and our main indications for use of the Columbus) are as follows:

1. Reaching occluded vessels in patients with acute ischemic stroke. In this scenario, the neuro guidewire must reliably and quickly reach the target in a safe manner. ${ }^{45}$ In most cases, this can be accomplished by using a J-configured microwire. The J curve prevents the wire from entering small perforating branches and usually follows the clot into the largest branch. This can typically be achieved using standard guidewires. However, when the tip curve does not allow access to the desired branch, it must be removed and reshaped.

2. Passing a wide-neck aneurysm into distal branches to ensure patency of arteries while treating an aneurysm with balloons or stents. ${ }^{6-10}$ When arteries rise from an aneurysm at a sharp angle, it can be challenging to access them directly. ${ }^{11}$ Experienced operators can loop the wire in the aneurysm to access these branches. ${ }^{12}$ However, this maneuver can be dangerous, especially in ruptured or in partially thrombosed aneurysms, as it can cause bleeding or displacement of thrombus.

\section{MATERIALS}

Recent technological progress has enabled the production of neuro guidewires with a nominal diameter of $0.014 "$, whose tip shapes can be manipulated while inside the patient.

The Columbus is a CE-marked 0.014" guidewire with a remotely controlled deflectable tip. Recently, it received Food and Drug Administration (FDA) clearance in the USA under the name 'Drivewire'. It is designed for neuronavigational purposes and 


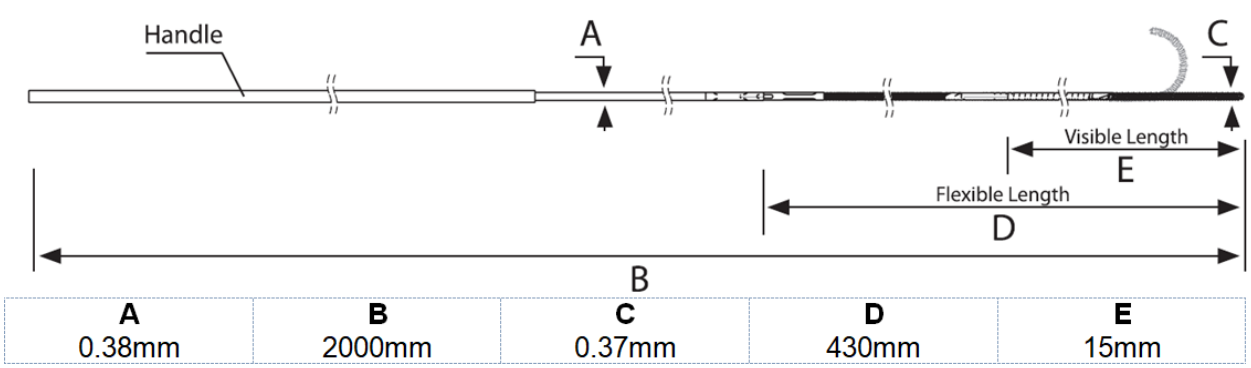

Figure 1 Schematic drawing of the small radius version.

designed and produced by Rapid Medical Ltd (Yokneam, Israel). To our knowledge, it is the only CE-marked and FDA-approved neuro guidewire with a deflectable tip available today. ${ }^{13} 14$ It is intended for use with straight conventional neuro microcatheters, which are compatible with 0.014 " wires. The overall length is $1925 \mathrm{~mm}$ in the standard version and $2000 \mathrm{~mm}$ in the small radius (SR) version. It comprises a proximal handle with a diameter of $0.015 "$, a shaft section, a flexible section $(430 \mathrm{~mm})$, and a distal adjustable tip section $(15 \mathrm{~mm})$ (figure 1$)$.

A micro core wire passes through the Columbus and is connected to the handle on the proximal end and to the tip on the distal end. The tip can be deflected or shaped by pulling or pushing the handle. Pulling on the handle will decrease the radius and will curve the tip, while pushing the handle will increase the curvature radius and will straighten the tip until it bends into the opposite direction. The handle automatically maintains its last position and locks the tip shape through the core wire. The amount of deflection is at the discretion of the operator (figure 2). In general, the shaping and support for the microcatheter are stronger when the handle is in the 'pull' position than when it is in the 'push' position. The movable inner core wire generates stronger support for microcatheters at the wire tip than conventional wires (figure 3).

When the handle is in the neutral position, the wire's tip is straight and floppy with a low tip force. Currently, two versions of the Columbus guidewire are available: the standard Columbus

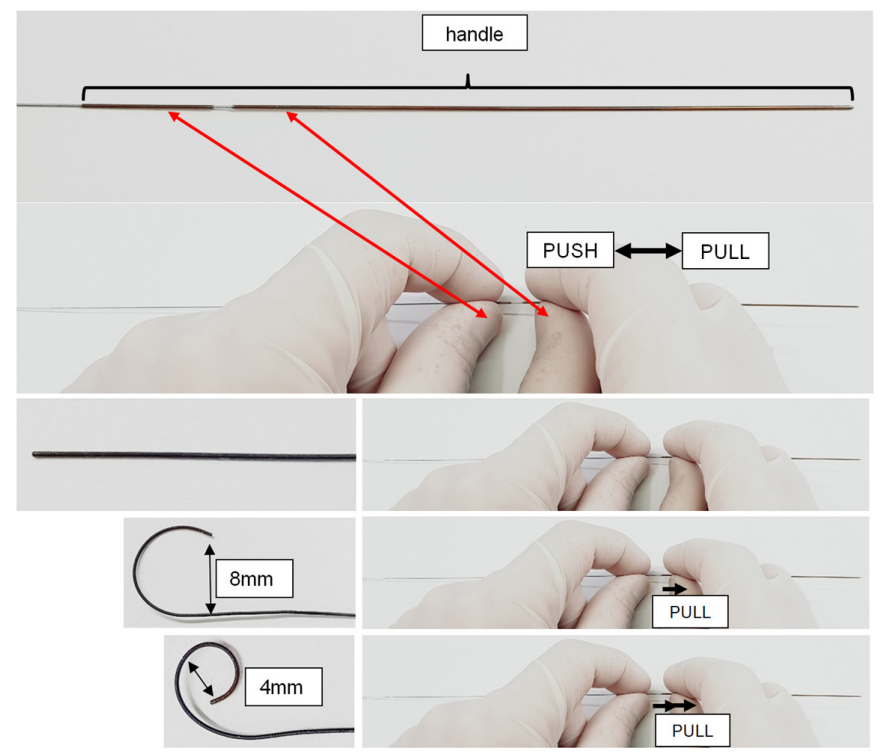

Figure 2 The tip is deflected into the desired shape by pulling or pushing the proximal handle. Tip deflection control eliminates the need for tip shaping over a mandrel. guidewire with a deflectable tip radius of $8 \mathrm{~mm}$ and the Columbus SR guidewire with a radius of $4 \mathrm{~mm}$.

\section{METHODS}

\section{Patient selection}

Between August 2019 and December 2020, neurovascular treatments in 36 patients were performed using the Columbus guidewire. The following interventions were executed:

- Treatment of cerebral aneurysms $(n=17)$

- Four ruptured aneurysms: These were treated with either stent/balloon-assisted coiling $(n=2)$, Y-stenting and coiling $(n=1)$, or plain coiling $(n=1)$.

- Another 13 were unruptured and treated with either a flow diverter $(n=5)$, an intrasaccular flow disruptor $(n=1)$, stent-assisted coiling $(n=6)$, or plain coiling $(\mathrm{n}=1)$.

Thrombectomy in acute ischemic stroke $(n=12)$

- Within anterior circulation $(n=11)$ or posterior circulation $(n=1)$

- Other $(\mathrm{n}=7)$

- Preoperative embolization of meningioma $(n=2)$, carotid stenting $(n=1)$, intracranial stenting $(n=1)$, treatment of vasospasm $(n=1)$, embolization of arteriovenous malformation $(n=1)$, and embolization of dural arteriovenous Fistula $(n=1)$

Informed consent was obtained from all individual participants included in the study. This study was approved by the local ethical committee

\section{Procedure}

Patients were individually selected based on the preinterventional planning and technical considerations of the interventionists. All
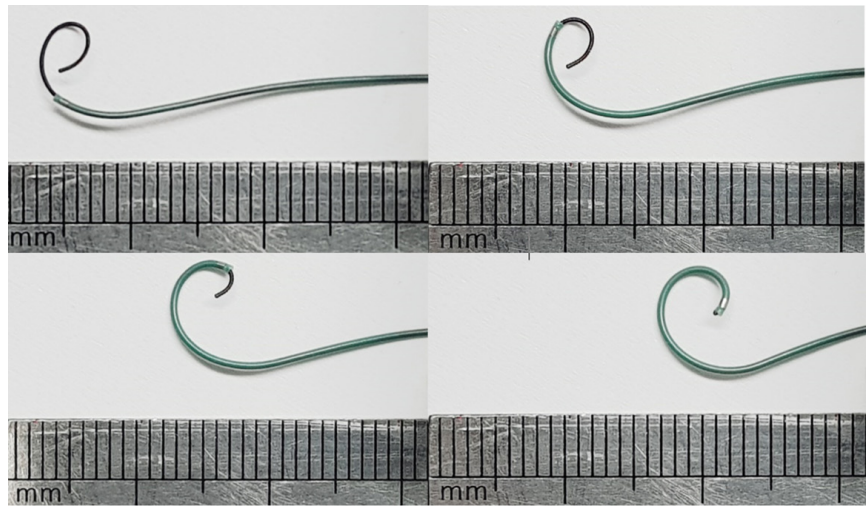

Figure 3 Example of internal support of the wire tip for a microcatheter: Columbus shapes a straight SL-10 microcatheter and allows advancement without forerun. 
interventions were performed by $\mathrm{AvH}$ or GK. Guiding catheters were used in all cases with standard femoral arterial access. All elective cases were performed under general anesthesia; acute ischemic stroke interventions and carotid artery stenting procedures were performed under conscious sedation whenever feasible.

\section{Follow-up and clinical evaluation}

Immediate follow-up with digital subtraction angiography was conducted in each patient with magnified series in the working projection and standard overview series in anteroposterior and lateral projections. The standard frame rate was two frames per second.

The outcomes of all patients treated with the Columbus guidewire were evaluated in retrospect. We recorded the angiographic procedures and the occurrence of any adverse events, both technical and clinical. Owing to the heterogeneity of cases treated, we deliberately refrain from reporting modified ranking scores, as disease progression depends primarily on the patient's baseline and we did not expect any influence from the guidewires used.

\section{RESULTS}

A detailed overview of all results is presented in table 1.

Thirty-six patients (20 female, 16 male) were treated with the Columbus guidewire (as a first-line wire in 35 cases), either solely or in conjunction with other devices. In 35 out of 36 cases, the Columbus reached the designated target vessel and its use and maneuverability were deemed successful by the interventionists. In one thrombectomy case, the Columbus guidewire reached the target vessel, but kinked and therefore could not deliver the microcatheter to the target. This application was considered unsuccessful, and the Columbus guidewire was replaced with another wire. In two cases (Nos 5 and 6), the Columbus guidewire was used as a secondary wire when the target vessel could not be cannulated with the primary wire. In both cases, the Columbus successfully reached the desired branches and advanced a microcatheter for stenting.

In five cases involving wide-base aneurysms, the Columbus guidewire enabled access to a critical branch in a direct path without requiring a dangerous looping maneuver in the aneurysm sac. In 15 cases, additional wires were used mainly owing to the nature of the procedures (eg, use of multiple wires, buddy wires or exchange maneuvers). In five cases, the Columbus guidewire was damaged by the operator during the intervention and had to be replaced. In one case, we intended to use the Columbus guidewire (nominal 0.014" wire) for carotid stenting but discovered that the balloon could not be back-loaded on the wire since the handle is too large to fit through the standard balloons/stents compatible with 0.014 " systems. This was considered an operator error, and the procedure was completed uneventfully using another wire.

The Columbus was successful in 35 out of 36 cases (target vessel reached), unsuccessful in one case (target vessel could not be reached with microcatheter), and none of the two complications encountered was associated with the Columbus wire.

\section{Complications and device failures}

In two cases, the handle came off the Columbus guidewire. No excessive force was applied in either case. The Columbus was removed and exchanged with another wire in one case and with another Columbus in the other case. Both procedures were then completed uneventfully. The detachment of the handle was reported to Rapid Medical. A technical solution to this problem has already been found and will be implemented in upcoming versions of Columbus and Columbus SR.

In two cases, complications occurred but were not directly related to the use of the Columbus guidewire. In one patient (No 6), active bleeding occurred after an Atlas stent was placed under dual antiplatelet therapy. The bleeding was controlled by coiling the aneurysm, but the hematoma was compressive and had to be surgically removed. After evacuation of the hematoma (and a pause of the antiplatelets), the stent occluded and could not be reopened; the patient had an additional stroke and was discharged to a nursing home with a modified Ranking Score of 5 and died 6 months later owing to pneumonia complication.

In the other case, a coil was stretched during coiling but was removed successfully without adverse consequences for the patient.

\section{Subjective evaluation}

Our subjective assessment of the wire is ambivalent. Some properties of the Columbus are considerably inferior to those of standard guidewires. First and foremost, the wire's rotatability is inferior to that of standard wires in both versions, even with only slight shaping of the wire tip via the handle. With the help of the included torque device, the Columbus can certainly be rotated, but the wire's response to rotational movements and thus its controllability are inferior to existing guidewires. The rather abrupt transition of the very soft tip into the stiff stainless-steel shaft makes inserting the wire into the Y-connector a bit more difficult and takes longer to become familiar with. However, an insertion aid can be dispensed with, since the wire can be straightened for insertion without any problems and then be shaped in the patient using the handle. Both the shaft and the handle at the end of the Columbus are quite sensitive and require great care to avoid damage. The visibility of the wire under fluoroscopy is good and the tip of the wire is extremely soft when directed anteriorly. We had no hesitation, for example, in probing even ruptured aneurysms with this wire. Furthermore, some features-namely, the incredibly strong support of the shaped tip, exceeded our expectations and allowed maneuvers probably not possible with conventional wires (eg, in the cases 5, 6, 35, and 36). Particularly in wide-base aneurysms with branches coming off at a sharp angle, the Columbus proved extremely effective in avoiding dangerous maneuvers that require looping in the aneurysm. In one case (No 5), it was also possible to place a microcatheter in a J-configuration using Columbus, which was also a very helpful maneuver to access a branch (at a $>150$ degree angle to the carrier vessel). Additionally, the ability to manipulate the tip while in the vessel was helpful in three cases $(5,24$, and 27$)$ and seems to offer potential for new maneuvers. The features of the wire could practically eliminate the need for wire retractions, which are routinely performed to reshape traditional guidewires and thus lower the risk of introducing air emboli into the circulation. In patients with a stroke, the ability to obtain a J-configuration of the wire on demand was particularly advantageous. Nevertheless, this advantage was at least partially canceled out by the wire's poor rotatability.

Navigating in intracranial vessels requires, that the operator be willing to adapt to the special properties of the Columbus wire and to primarily use the handle and the formability of the wire tip to steer rather than navigating as usual by rotating and pushing forward/backward. Operators who are not prepared to accept these requirements will probably not use the Columbus wire. 
New devices and techniques

Table 1 Overview of the interventions in which the Columbus guidewire was used

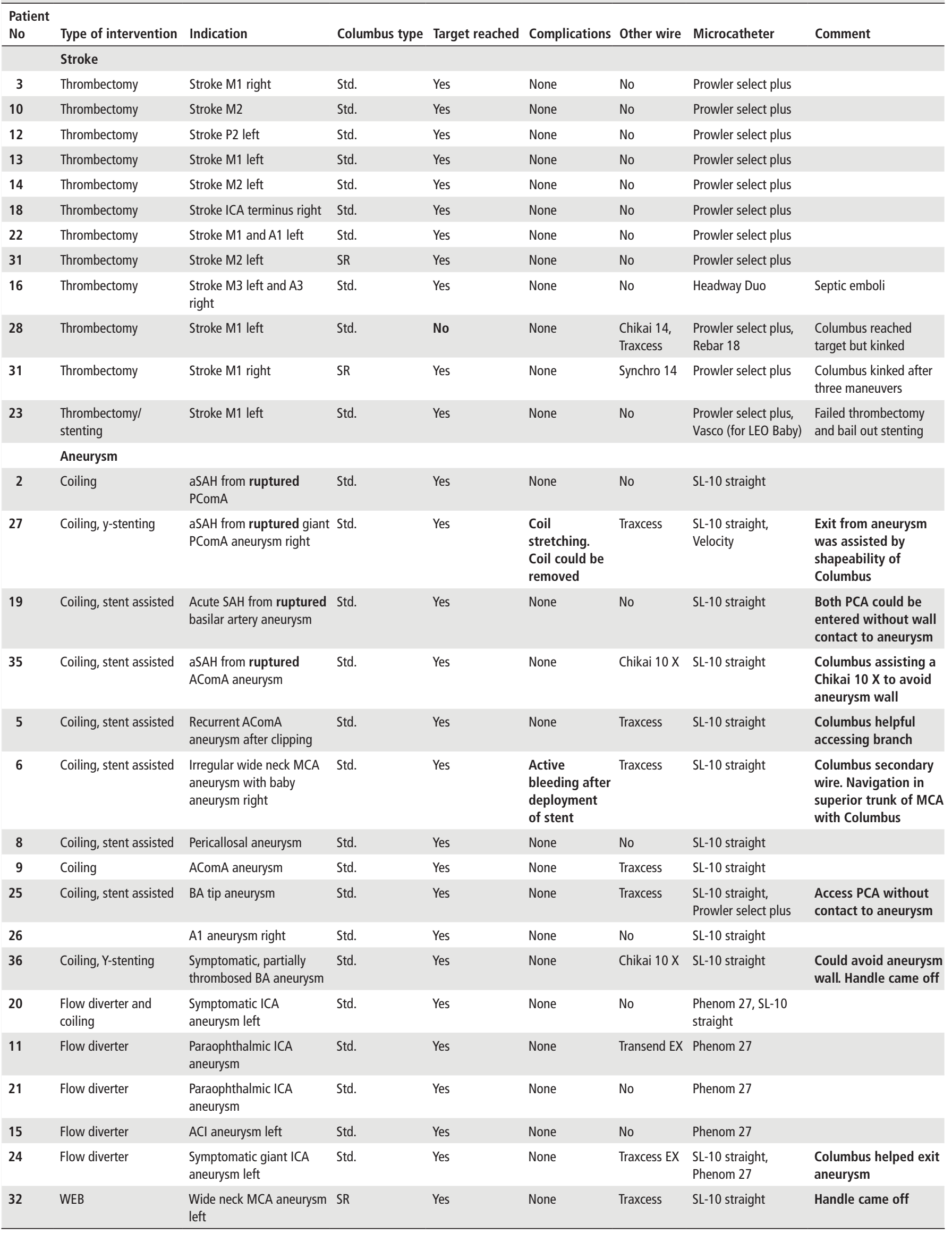




\begin{tabular}{|c|c|c|c|c|c|c|c|c|}
\hline $\begin{array}{l}\text { Patient } \\
\text { No }\end{array}$ & Type of intervention & Indication & Columbus type & Target reached & Complications & Other wire & Microcatheter & Comment \\
\hline & Other & & & & & & & \\
\hline 17 & Embolization & Ruptured thalamic AVM & Std. & Yes & None & $\begin{array}{l}\text { Chikai 8, } \\
\text { Traxcess }\end{array}$ & SL-10 straight & \\
\hline 7 & Embolization & $\begin{array}{l}\text { Symptomatic sigmoid } \\
\text { sinus AV-fistula }\end{array}$ & Std. & Yes & None & No & SL-10 straight & \\
\hline 1 & Embolization & $\begin{array}{l}\text { Giant meningioma pre- } \\
\text { operation }\end{array}$ & Std. & Yes & None & No & Rebar 27 & \\
\hline 34 & Embolization & $\begin{array}{l}\text { Giant meningioma pre- } \\
\text { operation }\end{array}$ & SR & Yes & None & No & Rebar 27 & \\
\hline 33 & $\begin{array}{l}\text { Treatment of } \\
\text { vasospasm }\end{array}$ & $\begin{array}{l}\text { aSAH from ruptured, } \\
\text { clipped MCA aneurysm }\end{array}$ & SR & Yes & None & No & Prowler select plus & Use of Comaneci \\
\hline 4 & Carotid stenting & $\begin{array}{l}\text { Symptomatic high-grade } \\
\text { stenosis left ICA }\end{array}$ & Std. & Yes & None & $\begin{array}{l}\text { Synchro } \\
14 \mathrm{EX}\end{array}$ & None & $\begin{array}{l}\text { Backloading devices } \\
\text { impossible }\end{array}$ \\
\hline 29 & Intracranial stenting & $\begin{array}{l}\text { Symptomatic high grade } \\
\text { stenosis M1 left }\end{array}$ & Std. & Yes & None & No & SL-10 straight & \\
\hline
\end{tabular}

The table is grouped by type of intervention.

AComA, anterior communicating artery; $\mathrm{S} A \mathrm{AH}$, acute subarachnoid hemorrhage; $\mathrm{AV}$, arteriovenous; $\mathrm{AVM}$, arteriovenous malformation; $B A$, basilar artery; ICA, internal carotid artery; ICA, internal carotid artery; MCA, middle cerebral artery; PCA, posterior cerebral artery; PComA, posterior communicating artery.

\section{Recommendations}

When using the included torque device, it is important to ensure that it is fastened as closely as possible to the Y-connector and not overtightened; otherwise, the functionality of the handle will be impaired. When torque is needed, we recommend turning the wire only in small steps of 90 degrees and assisting the torque transmission to the tip through tiny movements forward and backward.

Because of the weak control via torque, we recommend that, if necessary, the shape of the tip be manipulated primarily via the handle to enter the target vessel and not (as is common with other wires) to control the behavior of the wire through twisting movements.

To derive the maximum benefit from the support of the configured wire tip, we recommend using the smallest possible soft and non-preformed microcatheters. By securing the wire and simultaneously pushing the microcatheter (beyond the tip of the wire in a branch extending at a sharp angle), it is often possible to advance the microcatheter far enough into the target vessel to subsequently advance the relaxed wire beyond the curve.

For any procedure using the Columbus guidewire, keep in mind that the handle has a diameter greater than 0.014"; therefore, the guidewire is not suitable for threading balloons or stents from its distal end. In individual cases, especially with elongated vessels, another property of the Columbus guidewire was helpful: by pulling firmly on the handle, a strong bending of the wire tip can be achieved, which leads to a slight anchor effect in the vessel. This effect can be exploited to push a microcatheter forward to reach the target. However, this effect is not as strong as that of a stentriever. When removing the Columbus from a microcatheter, a pronounced configuration of the tip should be reversed by neutralizing the handle; otherwise, a high amount of friction will be created in the microcatheter, and it will also retreat when the wire is pulled.

\section{CONCLUSION}

The steerable Columbus (also known as Drivewire) offers significant advantages when support at the catheter tip is needed, a change of tip configuration is required within the patient, or a (light) anchoring of the microwire would be helpful. The exceptionally strong support of a microcatheter at the wire tip and its malleability in the patient makes the Columbus especially interesting in the treatment of broad-based aneurysms, where looping in the aneurysm sac should be avoided or where access to branches cannot be achieved with conventional wires. The on-demand J-configuration can be helpful in patients with a stroke where the thrombus must be reached quickly. However, the inferior rotatability of the current Columbus version compared with available standard wires is a serious disadvantage, which probably outweighs the benefit of the controllability of the wire tip in neurointerventional daily routine in many cases. Nevertheless, this new technology appears promising. Should it be possible to further improve the torquability and robustness of the Columbus guidewire to the level of the available standard wires, the wire could become a useful alternative to standard wires in various neurointerventions.

\section{Twitter Tomás Reyes del Castillo @tomrdc}

Acknowledgements We thank Rapid Medical for the support provided during this study.

Contributors AvH was the main author of the manuscript. TRdC and GK were major contributors in writing the manuscript and analyzing the data. JER provided administrative support and provided a critical review of the intellectual content of the article. All authors read and approved the final manuscript.

Funding The authors have not declared a specific grant for this research from any funding agency in the public, commercial or not-for-profit sectors.

Competing interests All authors read and approved the final manuscript. The Department of Radiology and Nuclear Medicine received an educational grant from Rapid Medical in 2020

Patient consent for publication Not required.

Ethics approval All procedures performed in studies involving human participants were in accordance with the ethical standards of the institutional and/or national research committee and with the 1964 Helsinki declaration and its later amendments or comparable ethical standards. Informed consent was obtained from all individual participants included in the study. This study was approved by the EKNZ (Ethikkomission Nordwest und Zentralschweiz) with the project ID: 2021-00276. 
Provenance and peer review Not commissioned; externally peer reviewed.

Data availability statement All data relevant to the study are included in the article or uploaded as supplementary information. Data are available upon reasonable request.

Open access This is an open access article distributed in accordance with the Creative Commons Attribution Non Commercial (CC BY-NC 4.0) license, which permits others to distribute, remix, adapt, build upon this work non-commercially, and license their derivative works on different terms, provided the original work is properly cited, appropriate credit is given, any changes made indicated, and the use is non-commercial. See: http://creativecommons.org/licenses/by-nc/4.0/.

\section{ORCID iD}

Tomás Reyes del Castillo http://orcid.org/0000-0002-3080-1568

\section{REFERENCES}

1 Griessenauer CJ, Foreman P, Deveikis JP, et al. Endovascular tools available for the treatment of cerebrovascular disease. Neurosurg Clin N Am 2014;25:387-94.

2 Kim J, Nguyen PB, Kang B, et al. A novel tip-positioning control of a magnetically steerable guidewire in sharply curved blood vessel for percutaneous coronary intervention. Int J Control Autom Syst 2019;17:2069-82.

3 Kang S, Lee DY. Hydraulically steerable micro guidewire capable of distal sharp steering. IEEE Trans Biomed Eng 2020;68:728-35.

4 Yeo LLL, Bhogal P, Gopinathan A, et al. Why does mechanical thrombectomy in large vessel occlusion sometimes fail? : A review of the literature. Clin Neuroradiol 2019;29:401-14.
5 Heider DM, Simgen A, Wagenpfeil G, et al. Why we fail: mechanisms and co-factors of unsuccessful thrombectomy in acute ischemic stroke. Neurol Sci 2020;41:1547-55.

6 Kellner CP, Chartrain AG, Schwegel C, et al. The bumper technique for advancing a large profile microcatheter. BMJ Case Rep 2017;2017:bcr2016012872.

7 Kacar E, Nas OF, Kaya A, et al. The gently pull-back technique for neck bypass in treatment of wide-necked internal carotid artery aneurysms: a report of three cases and review of the literature. Neuroradio/ J 2015;28:604-8.

8 Oran I, C inar C, Bozkaya H, et al. The rapid pull-back technique for navigation across a wide-necked aneurysm. A report of four cases. Interv Neuroradiol 2013;19:16-20.

9 Edwards L, Kota G, Morris PP. The sea anchor technique: a novel method to aid in stent-assisted embolization of giant cerebral aneurysms. J Neurointerv Surg 2013:5:e39.

10 Sheth SA, Patel NS, Ismail AF, et al. Republished: treatment of wide-necked basilar tip aneurysm not amenable to Y-stenting using the PulseRider device. J Neurointerv Surg 2016;8:e37.

11 Kan P, Wakhloo AK, Mokin M, et al. Techniques in distal access of wide-necked giant intracranial aneurysms during treatment with flow diversion. Surg Neurol Int 2015;6:284.

12 Effendi K, Sacho RH, Belzile F, et al. The wire anchor loop traction (Walt) maneuver. J Neurointerv Surg 2016;8:e7.

13 Clogenson HCM, Simonetto A, van den Dobbelsteen JJ. Design optimization of a deflectable guidewire. Med Eng Phys 2015;37:138-44.

14 Luboz V, Zhai J, Odetoyinbo T, et al. Simulation of endovascular guidewire behaviour and experimental validation. Comput Methods Biomech Biomed Engin 2011;14:515-20 